\section{Michigan Technological 18 8 5 University}

Michigan Technological University Digital Commons @ Michigan Tech

Global Conference of the Youth Environmental Alliance in Higher Education

Dec 9th, 3:53 PM - 4:04 PM

\title{
Session 2C Agrivoltaics: Exploring the Opportunities \& Barriers to Combined Solar and Agriculture Systems
}

Alex S. Pascaris

Follow this and additional works at: https://digitalcommons.mtu.edu/yeah-conference

\section{Recommended Citation}

Pascaris, Alex S., "Session 2C Agrivoltaics: Exploring the Opportunities \& Barriers to Combined Solar and Agriculture Systems" (2020). Global Conference of the Youth Environmental Alliance in Higher Education. 38.

https://doi.org/10.37099/mtu.dc.yeah-conference/2020/all-events/38 


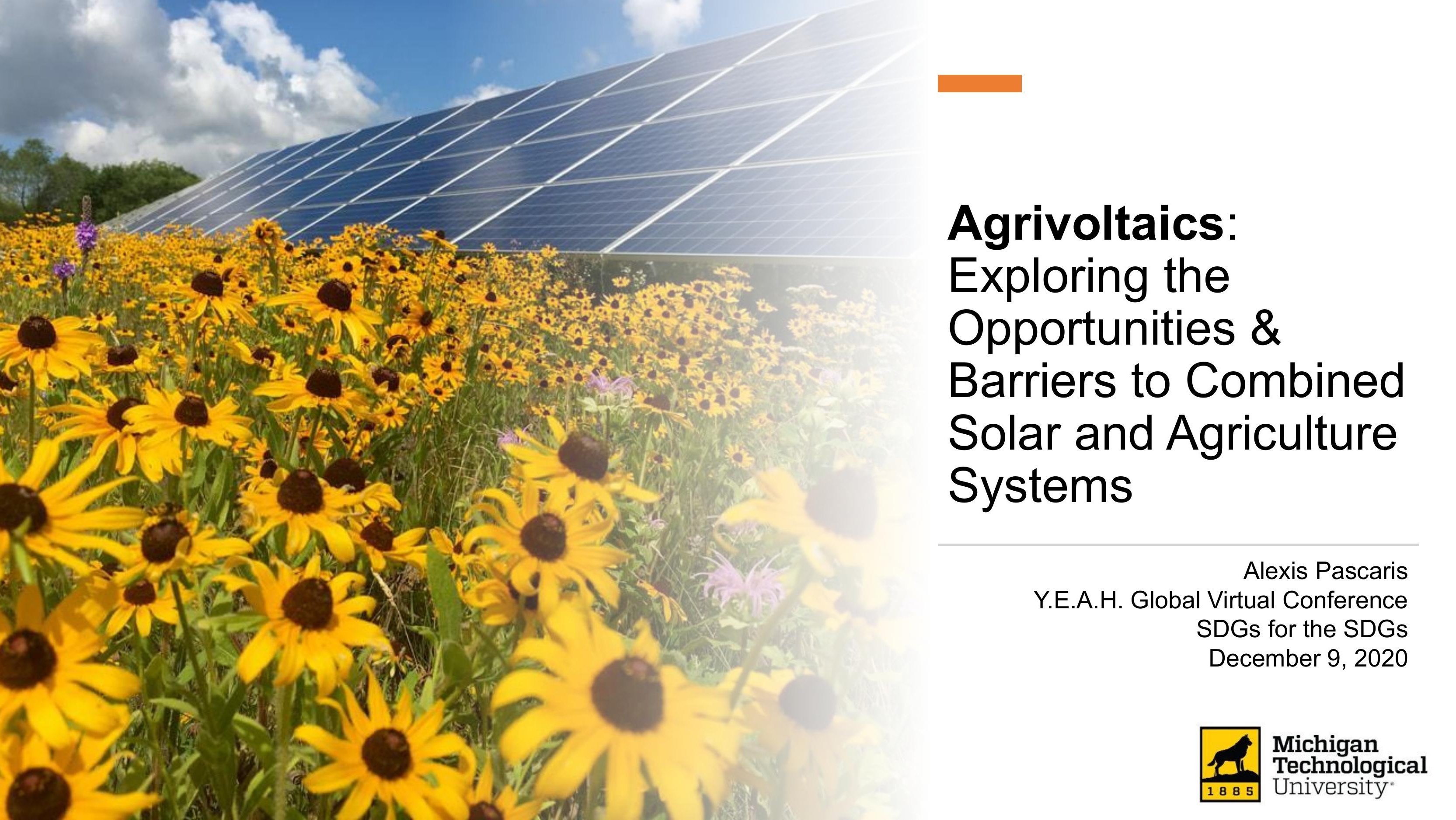




\section{Meet the Researcher}

Alexis Pascaris

- M.S. in Environmental \& Energy Policy (expected spring 2021)

Michigan Tech

( Research interests: Agrivoltaics, Solar PV, Renewable energy transitions, Sustainable communities, Environmental protection, Land conservation, Climate law \& governance

( B.S. in Environmental Studies \& Sustainability

$\checkmark$ Michigan State University 


\section{Presentation Outline}

Introduction to Agrivoltaics

Research Strategy

Preliminary Findings

Concluding Discussion 


\section{A Holistic Approach}

\section{( Social}

૫ Two in-depth interview studies

(] Agriculture sector ${ }^{1}$

口 Solar industry professionals ${ }^{2}$

- Environmental

Q Life Cycle Assessment ${ }^{3}$

$\square$ Economic

C Pilot test study

- Grazing pasture-fed rabbits in Lubbock, Texas, U.S.

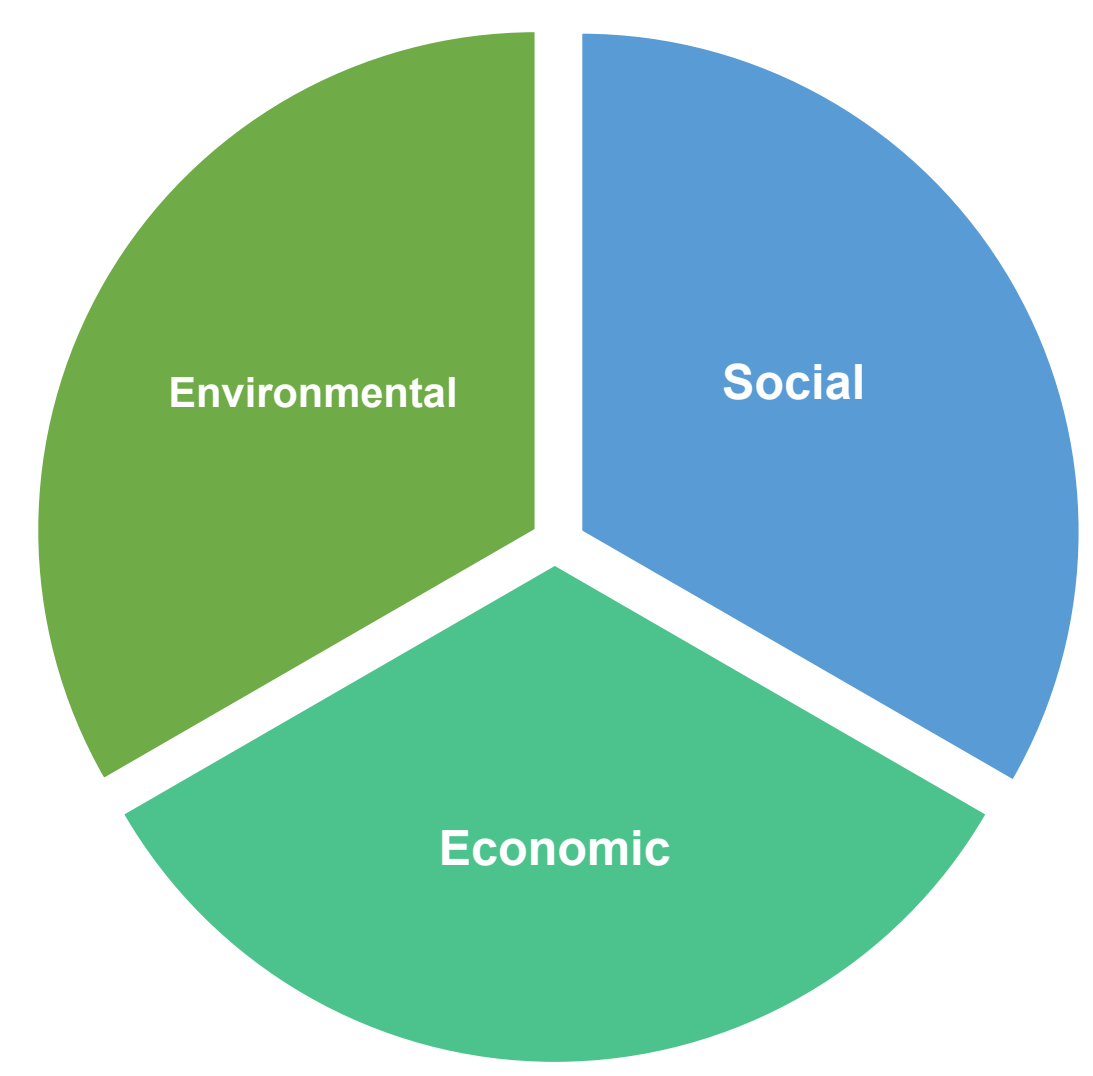




\section{Agriculture Sector \\ Findings: Interviews}

\section{Solar Industry}
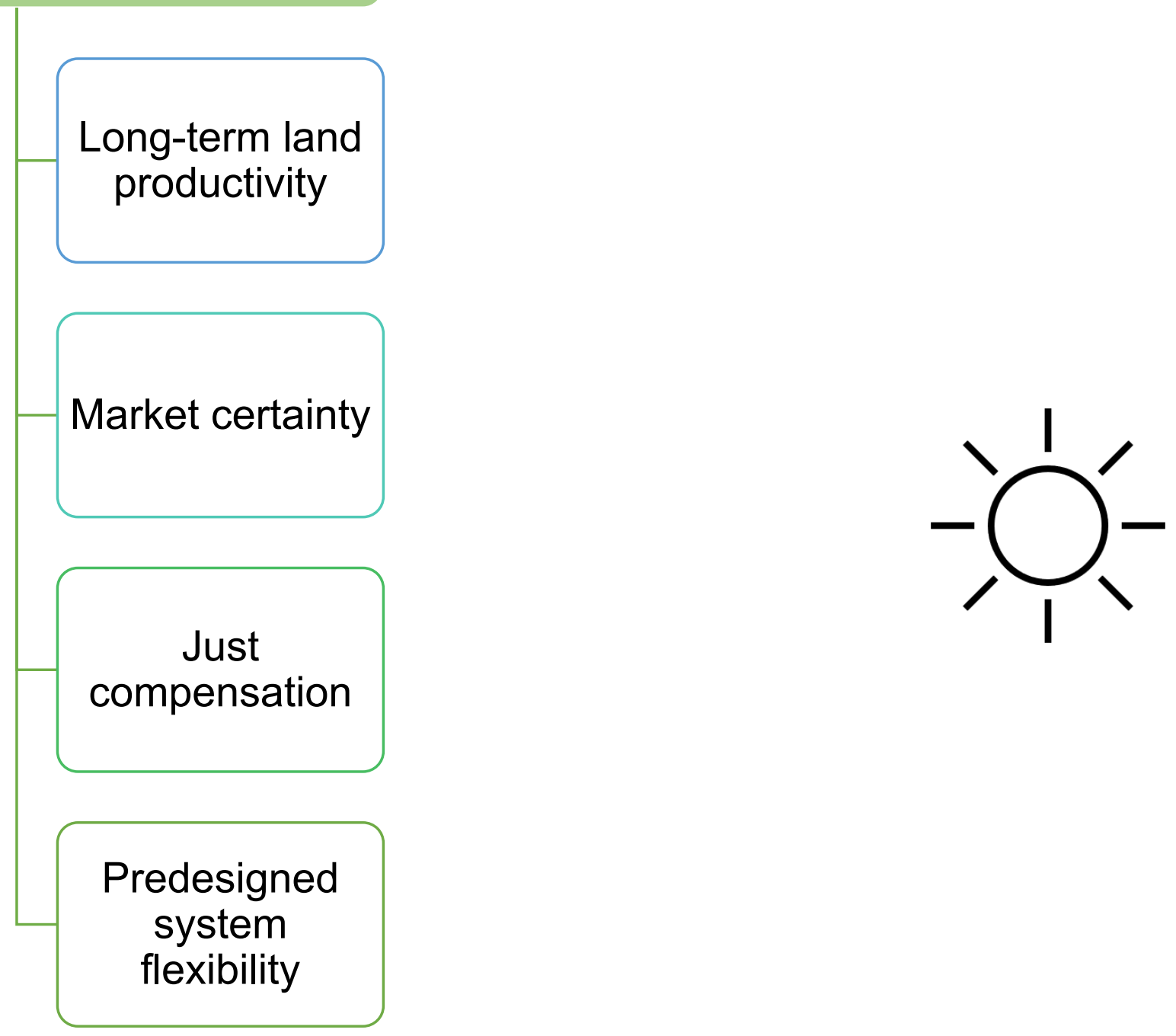

Accretive to the growth of solar

Potential to soften social resistance to development

\section{Economic} opportunities

Local level policy support is key 


\section{Life Cycle}

Assessment

1. Pascaris, A. S., Pearce, J. M. (2020) Life Cycle Assessment of a Novel Agrivoltaic Concept: The Case of Pasture-Fed Rabbits and Solar PV. Forthcoming

2. Lytle, W., Meyer, T. K., Tanikella, N. G., Burnham, i.. Engel, J. Śchelly, C. \&

Pearce, J. M. (2020). Ċonceptual design and

Pelore,

rationale for a new agrivoltaics concept:

Pastured-raised rabbits and solar

farming. Journal of Cleaner Production, 124476 .

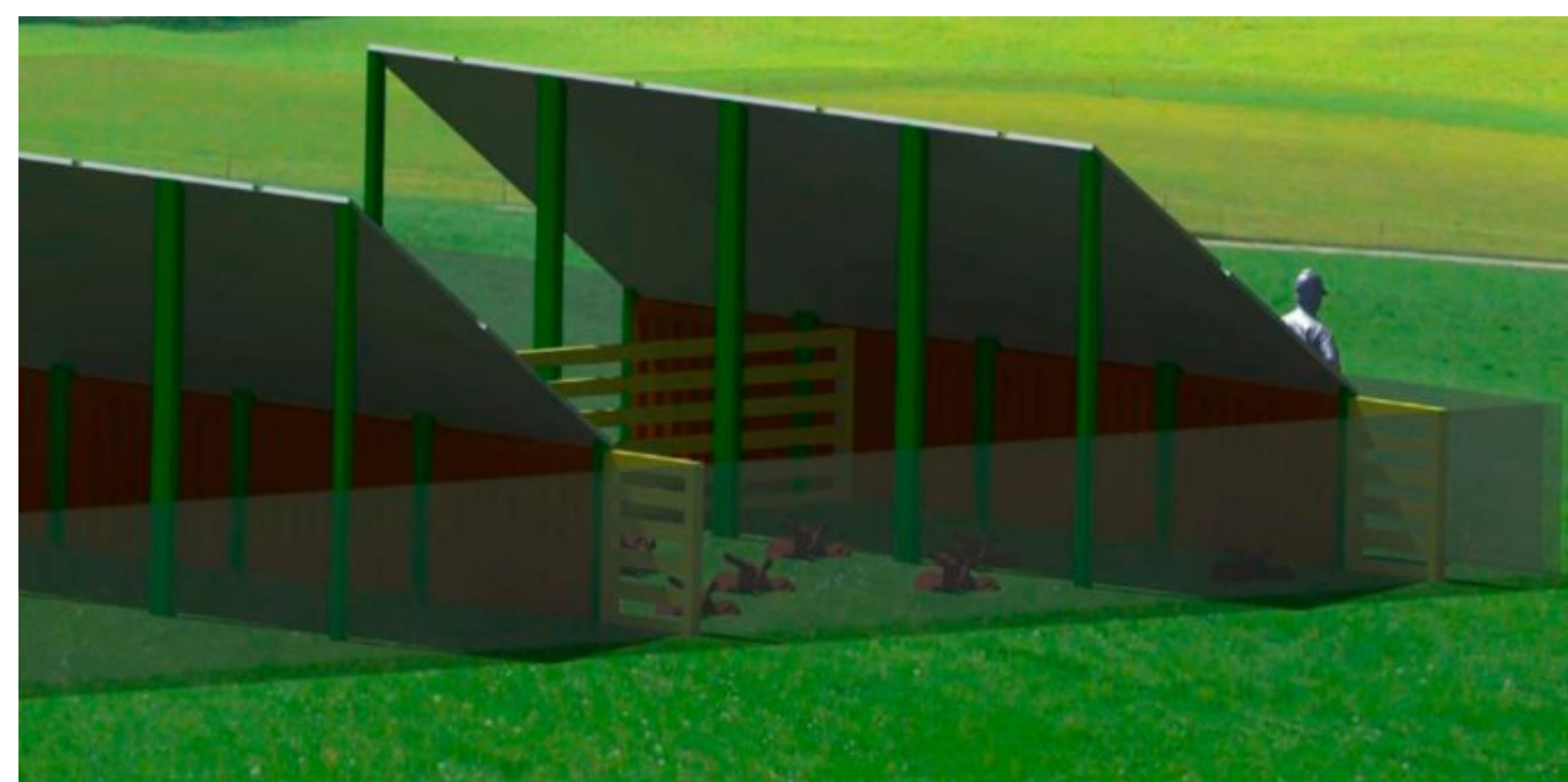

( SimaPro LCA modeling software

口 Modeled to achieve same level of service (electricity and meat output) through different means

(- Three systems studied:

1. Agrivoltaic model (pasture-fed rabbits + solar PV)

2. Independent model (conventional rabbits + solar PV)

3. Conventional rabbits + conventional electricity 


\section{Findings: Life Cycle Assessment}

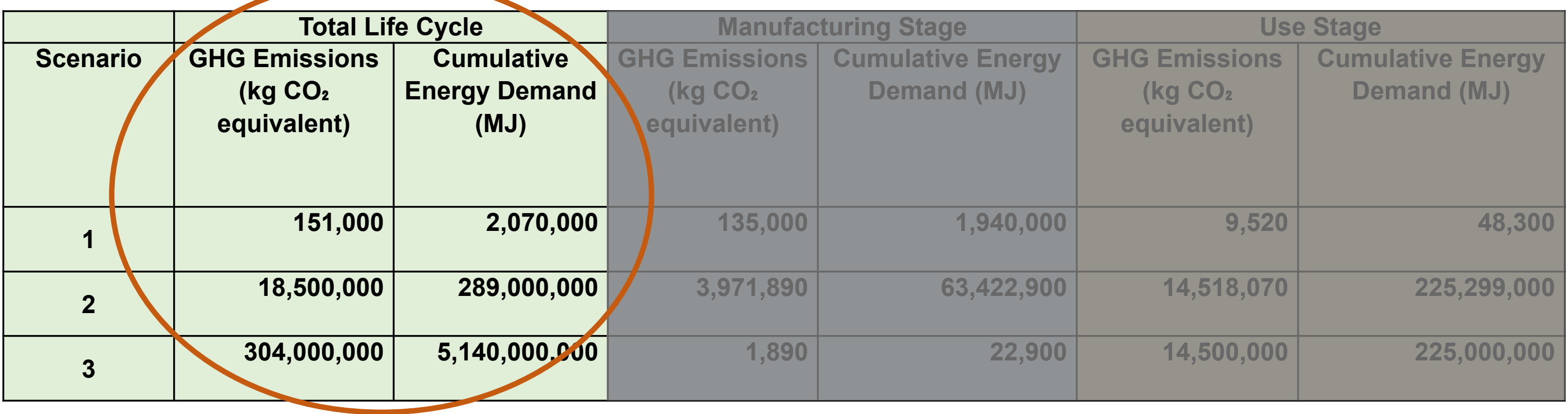

Scenario 1: Pasture-fed Rabbit Agrivoltaics

- Least total GHG emissions

- Least total Cumulative Energy Demand

Scenario 2: Independent Conventional

Rabbits + Solar PV

- Rabbit feed production

- Herbicide application to PV site

Pasture-fed agrivoltaics produces dual synergy! No reliance on energy intensive rabbit feed and no

vegetative maintenance required. 


\section{Concluding Remarks}

- SDG 12: Responsible Consumption and Production

- Technically and economically viablewhat's next?

- Forthcoming: Legal Framework Analysis, Policy Action

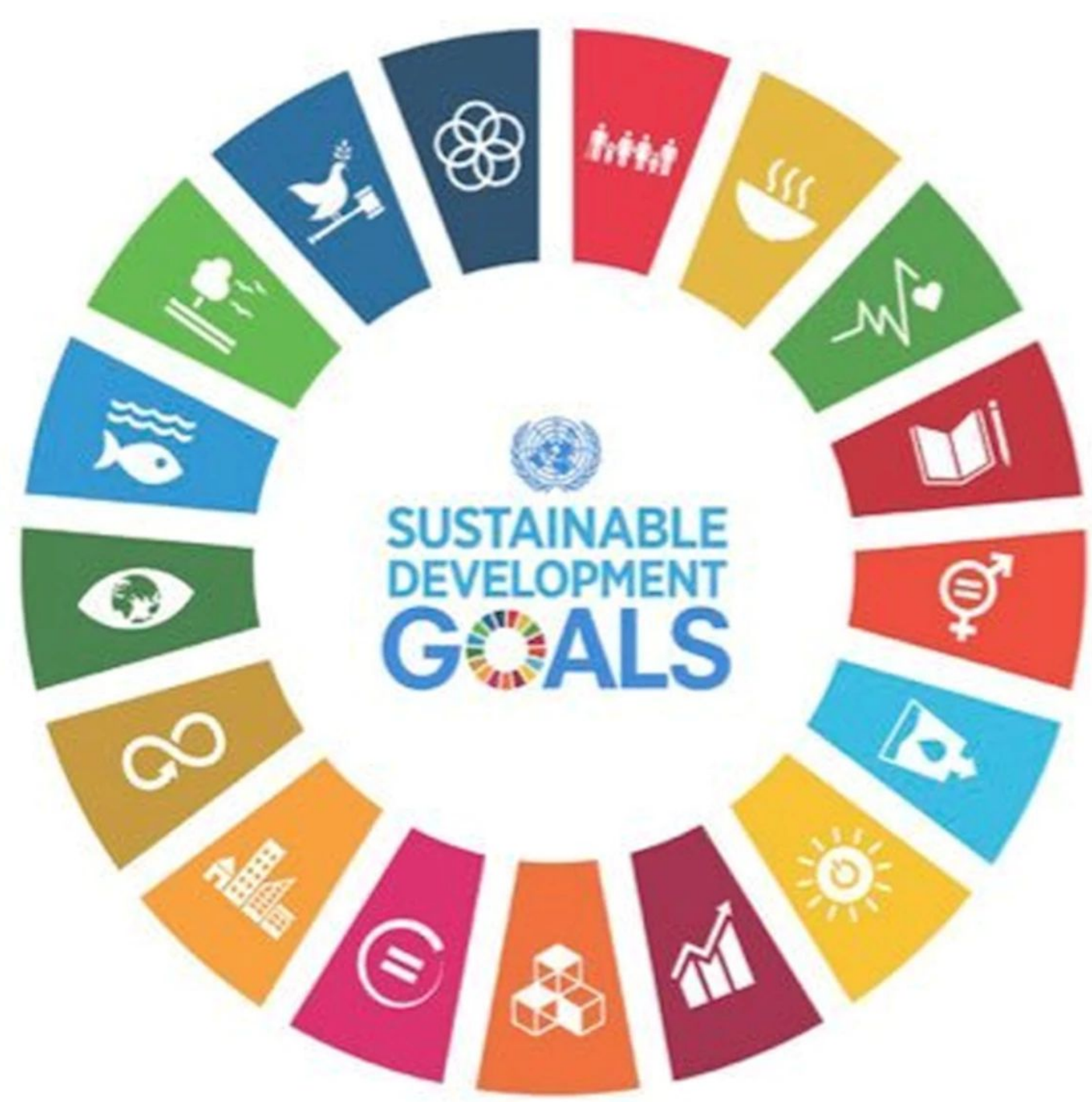




\section{Acknowledgements}

- Thank you to our project partners:

- Laurie Burnham of Sandia National Laboratories

- Mark Harral of GroupNIRE

- Julie Engel of The Pasturage, LLC

- Chart House Energy

- This material is based upon work supported by the U.S. Department of Energy's Office of Energy Efficiency and Renewable Energy (EERE) under the Solar Energy Technology Office Award Number DE-EE0008990.

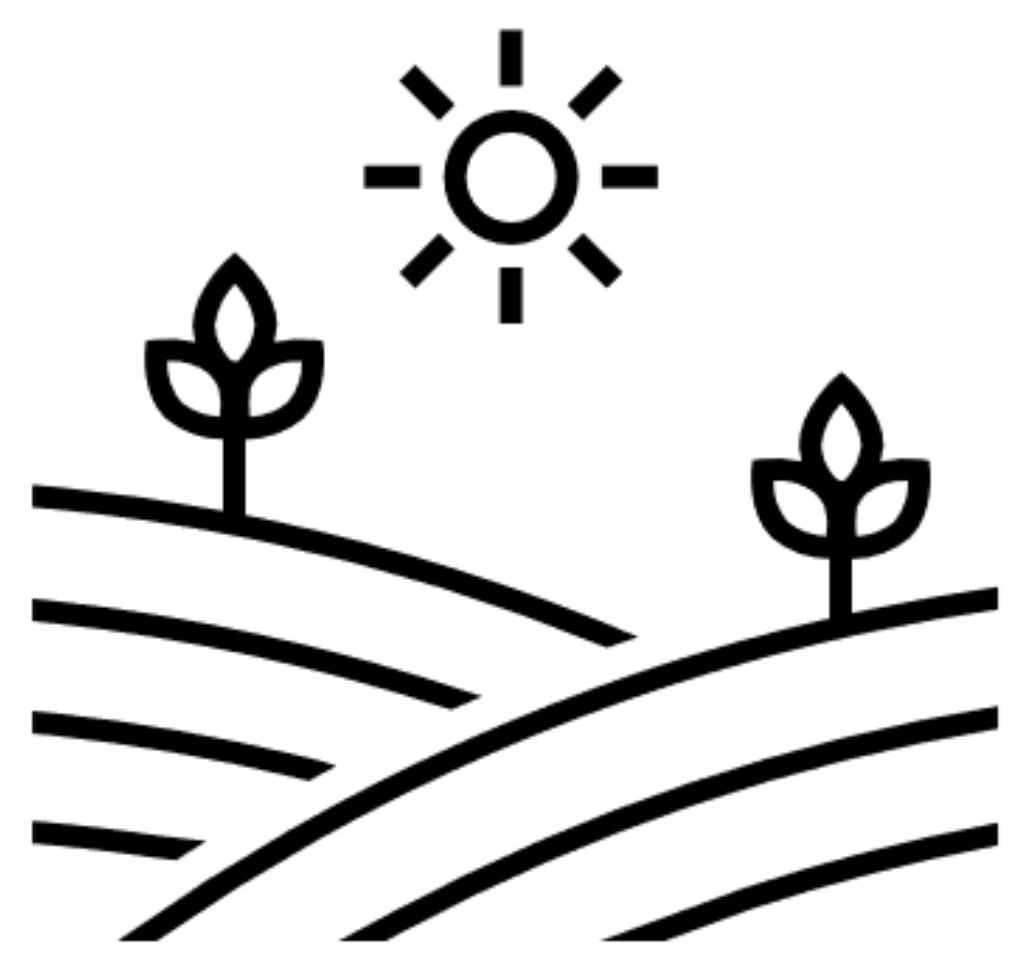

